\title{
Odonto-tricho-ungual-digito-palmar syndrome
}

INSERM

\section{Source}

INSERM. (1999). Orphanet: an online rare disease and orphan drug data base. Odontotricho-ungual-digito-palmar syndrome. ORPHA:69082

Odonto-tricho-ungual-digito-palmar syndrome is characterised by neonatal teeth, trichodystrophy and malformations of the hands and feet. To date, it has been reported in 21 patients and is transmitted as an autosomal dominant trait. 